\title{
Effect of Free Water Molecules on the Structure of Mg-ATP- Dipyridylamine and Overview on Selected Metal-Adenosine Triphosphate Structures in Model Compounds and in Enzymes
}

\author{
G. Tamasi ${ }^{\mathrm{a}}$, F. Berrettini ${ }^{\mathrm{b}}$, M.B. Hursthouse ${ }^{\mathrm{c}}$ and R. Cini ${ }^{\mathrm{a}, *}$ \\ ${ }^{a}$ Department of Chemistry, University of Siena, Via Aldo Moro 2, I-53100 Siena, Italy \\ ${ }^{b}$ Center for the Analysis and the Structural Determination, CIADS, University of Siena, Via Aldo Moro 2, I-53100 \\ Siena, Italy \\ ${ }^{c}$ School of Chemistry, University of Southampton, Southampton, SO17 1BJ, United Kingdom
}

\begin{abstract}
The X-ray diffraction (XRD) structures for new isoforms of $\left[\mathrm{M}\left(\mathrm{H}_{2} \mathrm{O}\right)_{6}\right] \cdot\left[\mathrm{M}(\mathrm{HATP})_{2}\right] \cdot 2(\mathrm{HDPA}) \cdot \mathrm{xH}_{2} \mathrm{O}, \mathrm{ATP}=$ adenosine 5'-triphosphate, DPA =2,2'-dipyridylamine, $\mathrm{M}=\mathrm{Mg}(\mathrm{II}), \mathrm{x}=6 \mathrm{H}_{2} \mathrm{O}, \mathbf{1}, \mathrm{M}=\mathrm{Ca}(\mathrm{II}), \mathrm{x}=8 \mathrm{H}_{2} \mathrm{O}, 2$ were determined by using rotating anode on molybdenum target X-ray source and Kappa CCD with confocal focusing mirror. The accuracy of the presently refined structure for $\mathbf{1}$ is the highest reported so far based on agreement factors $(\mathrm{R} 1=0.0579)$ and estimated standard deviations (esds) on geometrical parameters. The comparative analysis was extended to the structures of other low molecular weight metal-triphosphate complexes, to the structures of metal-triphosphate-protein systems as well as to computed models of metal-triphosphate complexes. The structures of $\mathbf{1}$ and $\mathbf{2}$ reported in this work show that on changing the number of co-crystallized water molecules, the interaction of the metal to the phosphate chain (for 1) and the conformation of ribose (for 2) undergo subtle but significant changes. Interestingly, the vast majority of Mg-nucleoside triphosphate (NTP)-enzyme systems have similar pattern of coordination to the phosphate chain when compared to $\mathbf{1}$ and 2. The three phosphate groups have variable M-O bond distances, depending on the systems. The structures for $\mathbf{1}$ and $\mathbf{2}$ have a high significance as general model compounds for experimental solid state and computations for these types of biological systems.
\end{abstract}

Keywords: Single-crystal X-ray diffraction, Adenosine triphosphate, ATP, Adenosine diphosphate, Magnesium, Calcium, Metal ion.

\section{INTRODUCTION}

Molecular structures of nucleoside diphosphates (NDPs) and triphosphates (NTPs) either as free molecules (See Scheme 1 for the selected nucleosides and nucleotides and relevant numbering of atoms) and as ligands to metal ions and substrates to enzymes, is a field of continuous interest for biochemists and coordination chemists, since almost forty years ago after the X-ray diffraction investigation on adenosine 5'-triphosphate sodium salt by Kennard et al. [1]. Sixty-eight hints were found on searching "crystal $A N D$ ATP $A N D$ magnesium" in PubMed [2] in the time period 1 January 2004 - 21 July 2009, and three hundred and thirty-six hints were found on searching "triphosphate $A N D$ magnesium" in PDB [3] in the same time period. These searches reveal that the interest on structural determinations for species that include magnesium and ATP or triphosphate, at large, is quickly increasing (See for example Ref [4-8]).

Nucleotides and metal-nucleotides are flexible particles and may assume a variety of conformations depending on the enzymes for which they behave as substrate, on the

*Address correspondence to this author at the Department of Chemistry, University of Siena, Via Aldo Moro 2, I-53100 Siena, Italy; Tel: 390577 234368; Fax: 390577 234254; E-mail: cini@unisi.it presence of specific metal ions, on the number of free water molecules, on the ionic strength, on the $\mathrm{pH}$ of medium, on temperature, etc. $[9,10]$. Nowadays, computational methods suitable for simulating molecular dynamics of small metalnucleotide molecules, at high reliability levels [11], are accessible to most inorganic chemistry laboratories. Nevertheless, the computations often fail to adequately reproduce the effects of solvent, whereas the final geometry for optimized structures depend on the initial choices of coordination modes. Therefore, the efforts devoted to get detailed conformation results from experimental methods are still much worthy. Among all possible routes, single crystals X-ray diffraction is the most powerful one. Unfortunately, the high flexibility of the molecules, the presence of several protonation sites and metal donor sites, as well as the presence of many easily breakable bonds (like glycosidic (base)N$\mathrm{C}$ (sugar), and phosphate chain $\mathrm{P}-\mathrm{O}(\mathrm{P})$ bonds), make the task of preparing suitable single crystals a very difficult one. Thus, the number of X-ray diffraction structures for NDPs/NTPs reported so far is small. Encouragingly, devices for collection of X-ray data sets and computing facilities for structure solutions and refinements are quickly improving.

The structures of M-NTPs (as new isoforms), namely $\mathrm{Mg}^{2+} / \mathrm{Ca}^{2+}$-adenosine 5'-triphosphate, $\mathrm{Mg} / \mathrm{CaATP}$, that have linking interactions between the metal ions and the nucleo- 

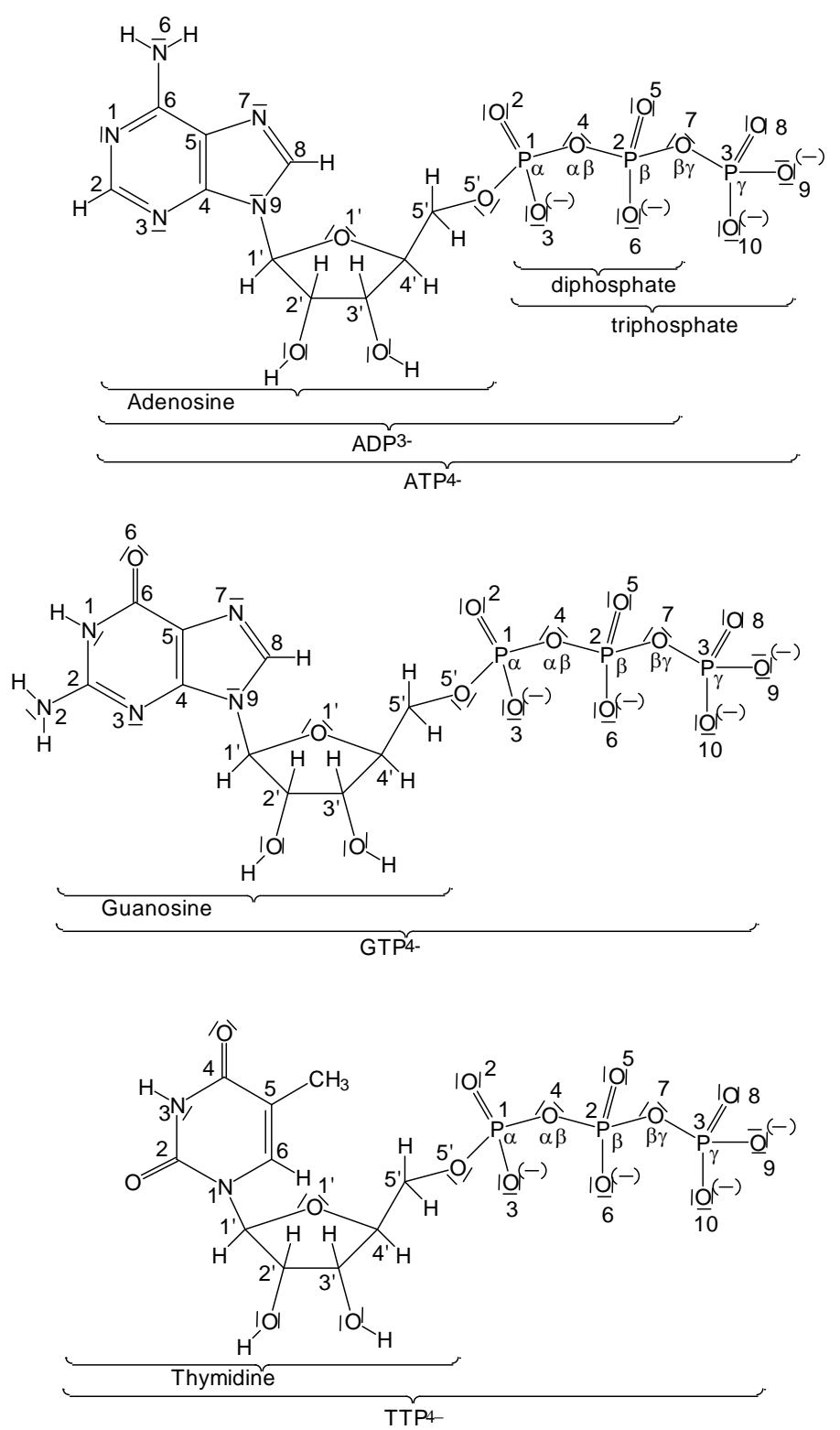

Scheme 1. The formulas and numbering of atoms for the selected nucleosides and nucleotides mentioned in this paper.

tide molecule via the phosphate oxygen only, previously reported [12,13], were studied with the aim to shed light on the role of free water molecules. Room temperature data collection were done via a conventional source Siemens P4 diffractometer, and (in subsequent data collections) by using a Bruker Nonius FR 591 rotating anode with molybdenum target and a Nonius Kappa CCD with confocal focusing mirrors. The compounds have formulas: $\left[\mathrm{M}\left(\mathrm{H}_{2} \mathrm{O}\right)_{6}\right][\mathrm{M}$ $\left.(\mathrm{HATP})_{2}\right] \cdot 2(\mathrm{HDPA}) \cdot \mathrm{xH}_{2} \mathrm{O}, \mathrm{M}=\mathrm{Mg}(\mathrm{II}), \mathbf{1}(\mathrm{x}=12,6), \mathrm{M}=$ $\mathrm{Ca}(\mathrm{II}), 2(\mathrm{x}=8)$. It has to be noted that the CSD (Cambridge Structural Data Base) [14] does not report any structural determination relevant to low molecular weight magnesiumATP species other than that of formula $\left[\mathrm{Mg}\left(\mathrm{H}_{2} \mathrm{O}\right)_{6}\right][\mathrm{Zn}$ $\left.(\mathrm{HATP})_{2}\right]_{2} \cdot(\mathrm{HDPA}) \cdot 12 \mathrm{H}_{2} \mathrm{O}$ [15]. The present paper wishes to comment also a few selected structural studies for low molecular weight species, recently reported in the literature, in order to analyze nucleotide conformation and patterns of metal binding. The analysis includes also the selected structures of NTPs embedded in high molecular weight systems (enzymes).

\section{EXPERIMENTAL SECTION}

\section{Materials}

Adenosine 5'-triphosphate sodium salt tetrahydrate, $\mathrm{Na}_{2} \mathrm{H}_{2} \mathrm{ATP} \cdot 4 \mathrm{H}_{2} \mathrm{O}$, 2,2'-dypiridylamine, DPA, magnesium sulfate heptahydrate and calcium nitrate tetrahydrate were purchased from Life Sigma-Aldrich (Gallarate, Milan, Italy; purity for all compounds $\geq 99 \%$ ) just before the synthesis of the ternary metal compounds.

\section{Synthesis, Crystal Growth, and X-ray Studies}

The procedure for the synthesis and preparation of crystals suitable for X-ray diffraction studies was similar to that previously reported $[12,13]$. Crystalline DPA (34 mg, 0.2 $\mathrm{mmol})$ was added by $3 \mathrm{~mL} \mathrm{EtOH}(95 \% \mathrm{v} / \mathrm{v})$ and the clear 
solution was added by a fine powder of $\mathrm{Na}_{2} \mathrm{H}_{2} \mathrm{ATP} \cdot 4 \mathrm{H}_{2} \mathrm{O}$ (122 $\mathrm{mg}, 0.2 \mathrm{mmol}$ ); then ultra-pure water was dropped into the mixture under stirring, up to complete dissolution of the nucleotide. A solution of magnesium sulfate heptahydrate $(50 \mathrm{mg}, 0.2 \mathrm{mmol})$ or calcium nitrate tetrahydrate $(48 \mathrm{mg}$, $0.2 \mathrm{mmol}$ ) in $2 \mathrm{~mL}$ of ultra-pure water was then quickly added to the solution of the ligands and the final mixture was heated up to $65^{\circ} \mathrm{C}$ under stirring and maintained to that temperature for ca $10 \mathrm{~min}$. The final solution was stored at room temperature and then let concentrating via spontaneous evaporation of the solvent. Colorless well shaped parallelepiped crystals formed within $24 \mathrm{~h}$. They were filtered off from the mother liquor, rinsed with a few drops of cold water, and finally stored at $5^{\circ} \mathrm{C}$ in a sealed vial.

Crystals of sizes ca $0.20 \times 0.10 \times 0.10 \mathrm{~mm}^{3}(\mathrm{Mg}(\mathrm{II}), \mathbf{1})$ and $0.30 \times 0.15 \times 0.15 \mathrm{~mm}^{3}(\mathrm{Ca}(\mathrm{II}), 2)$ were selected through the polarizing microscope, mounted on a thin glass fiber and then submitted to X-ray diffraction experiments.

One of the crystals from compound $\mathbf{1}$ was analyzed at $295 \pm 2$ K through a Siemens P4 diffractometer equipped with a conventional source of radiation that used a Mo anticathode working at $25 \mathrm{~mA}$ and $50 \mathrm{kV}$. The Mo-Ka radiation $(\lambda=0.71073 \AA)$ was selected through a graphite monochromator. The diffractometer (located at CIADS, Centro di Analisi e Determinazioni Strutturali, University of Siena) allowed to collect a total of 4122 independent reflections, 2969 of which were considered observed (I $>2 \sigma(\mathrm{I}))$. The data set was corrected for Lorentz-polarization effects. The absorption correction was applied by using the $\psi$-scan method based on the values of thirty reflections. The set of data is hereafter reported as DS2 whereas the corrected data set from Ref 13 is reported as DS1. The selected crystal data for DS2 are listed in Table 1. Structure solution and refinement (space group $\mathrm{C} 2221, \mathrm{n}^{\circ}$ 20) was performed via the direct methods and series of difference-Fourier and least-squares cycles. The procedure located all the not-hydrogen atoms. Two sets of three peaks each around a metal cation, were interpreted as the positions of oxygen atoms from disordered water molecules in the first coordination sphere of magnesium. Six more peaks were assigned to co-crystallized water molecules. The hydrogen atoms for ATP and DPA moieties were set in calculated positions via the HFIX/AFIX options of SHELXS/L-97 [16,17] implemented in WinGX [18,19] and they were left to ride on the atoms to which they are linked. The hydrogen atom linked to pyridyl $\mathrm{N}$-atom from $\mathrm{HDPA}^{+}$was assigned SOF 0.5. All the not-hydrogen atoms were refined with anisotropic thermal parameters, whereas the hydrogen atoms were treated isotropically. The final conventional agreement factors were R1 0.0711 and wR2 0.1658 based on the observed reflections. Owing to the disorder that affects the two $\mathrm{HDPA}^{+}$cations, the N1D(1) and $\mathrm{C} 1 \mathrm{D}(1)$ atoms were assigned the scattering factors for nitrogen and carbon whereas occupancies were fixed at 0.86 and 1.17 , respectively (the values were obtained through a trial and error procedure). Bond distances and angles of phosphate group and purine moieties suggest that the acidic proton for the HATP ${ }^{3-}$ ligand is disordered and resides both on a $\gamma$-phosphate oxygen atom and on $\mathrm{N} 1$ nitrogen atom from adenine. Thus, both $\mathrm{O} 8$ and $\mathrm{N} 1$ were considered protonated and the occupancies of both hydrogen atoms were fixed at 0.5 . The analysis of the molecular structure and molecular graphic computations were performed via PARST [20] and ORTEP3 [21]. All the computer programs were implemented under the WinGX package and the Microsoft Windows-XP operating systems.

Another crystal for 1 was analyzed first at $120 \pm 2 \mathrm{~K}$ by using a Nonius Kappa CCD area detector situated at the window of a rotating anode (EPSRC, National Crystallographic Service, School of Chemistry, University of Southampton, Southampton, UK), equipped with a low temperature device Oxford Instrument Cryo-stream [22,23]. All the attempts (even with other carefully selected crystals) did not produce reliable data sets. Attempts were performed also by carrying out the diffraction experiments with crystals encapsulated in thin capillaries as such, in thin capillaries that contained a drop of mother liquor, and finally covered by inert glue. In all the cases the results consisted of poor cell constant esds. Therefore, it was decided to perform the X-ray experiments at room temperature $(295 \pm 2 \mathrm{~K})$. The crystal that had been submitted before to the X-ray beam at $120 \pm 2 \mathrm{~K}$ for $4 \mathrm{~h}$, was then allowed to equilibrate up to $295 \pm 2 \mathrm{~K}$ for $12 \mathrm{~h}$ before performing full data collection at the latter temperature. In this case the refinement of the model reached the best result never reported for this series of structures (see below). Data were collected up to $2 \theta 55^{\circ}$ and processed through COLLECT [24] and DENZO [25] software packages, whereas absorption corrections were performed using SADABS [26]. This set of data is hereafter reported as DS3. The structure solution and refinement were carried out via SHELXS/L-97 [16,17] by using the direct methods followed by series of difference-Fourier synthesis and least-squares cycles. The atomic coordinates of the model (as well as those from DS2) were confirmed as close to those previously found and reported from this laboratory [13] from DS1. The non-hydrogen atoms were located and refined, the hydrogen atoms were set in calculated positions. The final refinement converged to final R1 and wR2 factors 0.0579 and 0.1578 , respectively.

The crystal for the calcium derivative, 2, was submitted to the X-ray beam at EPSRC and the measurements were performed at $295 \pm 2 \mathrm{~K}$ (see Table 1). The data sets from previous work [13] and from this work are named DS4 and DS5, respectively. The analysis was performed through the procedure above reported for $\mathbf{1}$. The final agreement factors R1 and wR2 converged to 0.0983 and 0.2579 , respectively.

\section{RESULTS AND DISCUSSION}

\section{Structural Results from Data Set DS 2 and DS 3}

Both the data sets are relevant to $\left[\mathrm{Mg}\left(\mathrm{H}_{2} \mathrm{O}\right)_{6}\right][\mathrm{Mg}$ $\left.(\mathrm{HATP})_{2}\right] \cdot 2(\mathrm{HDPA}) \cdot \mathrm{xH}_{2} \mathrm{O}(\mathrm{x}=12, \mathrm{DS} 2 ; \mathrm{x}=6, \mathrm{DS} 3)$. The conventional agreement $\mathrm{R} 1$ factor was significantly improved to 0.0711 (present work, DS2) from the value of 0.1110 reached in the previous work (DS1) [13], for the isoform with twelve molecules per $\operatorname{Mg}(\mathrm{HATP})_{2}{ }^{4-}$ unit. The analysis from DS2 has esds on bond distances that are ca one third those previously measured [13]. The data set DS3 gave even better results and esds are smaller by a factor 5 to 7 with respect to those previously reported. Interestingly, the cell volumes are: 7211(2), 7190(3) and 7004(3) $\AA^{3}$, for DS1, DS2 and DS3, respectively, in agreement with a smaller number of water molecules for DS3. The crystal probably underwent a shrinking while under the stream of nitrogen 
Table 1. The selected Crystallographic Parameters and Experimental Data for $\left[\mathrm{M}_{(}\left(\mathrm{H}_{2} \mathrm{O}\right)_{6}\right] \cdot\left[\mathrm{M}\left(\mathrm{HATP}_{2}\right] \cdot \mathbf{2}(\mathrm{HDPA}) \cdot \mathbf{x H} \mathrm{O}, \mathbf{M}=\mathbf{M g}\right.$,

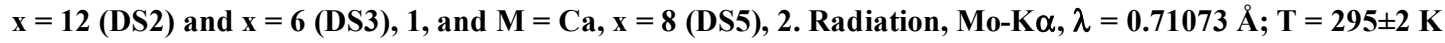

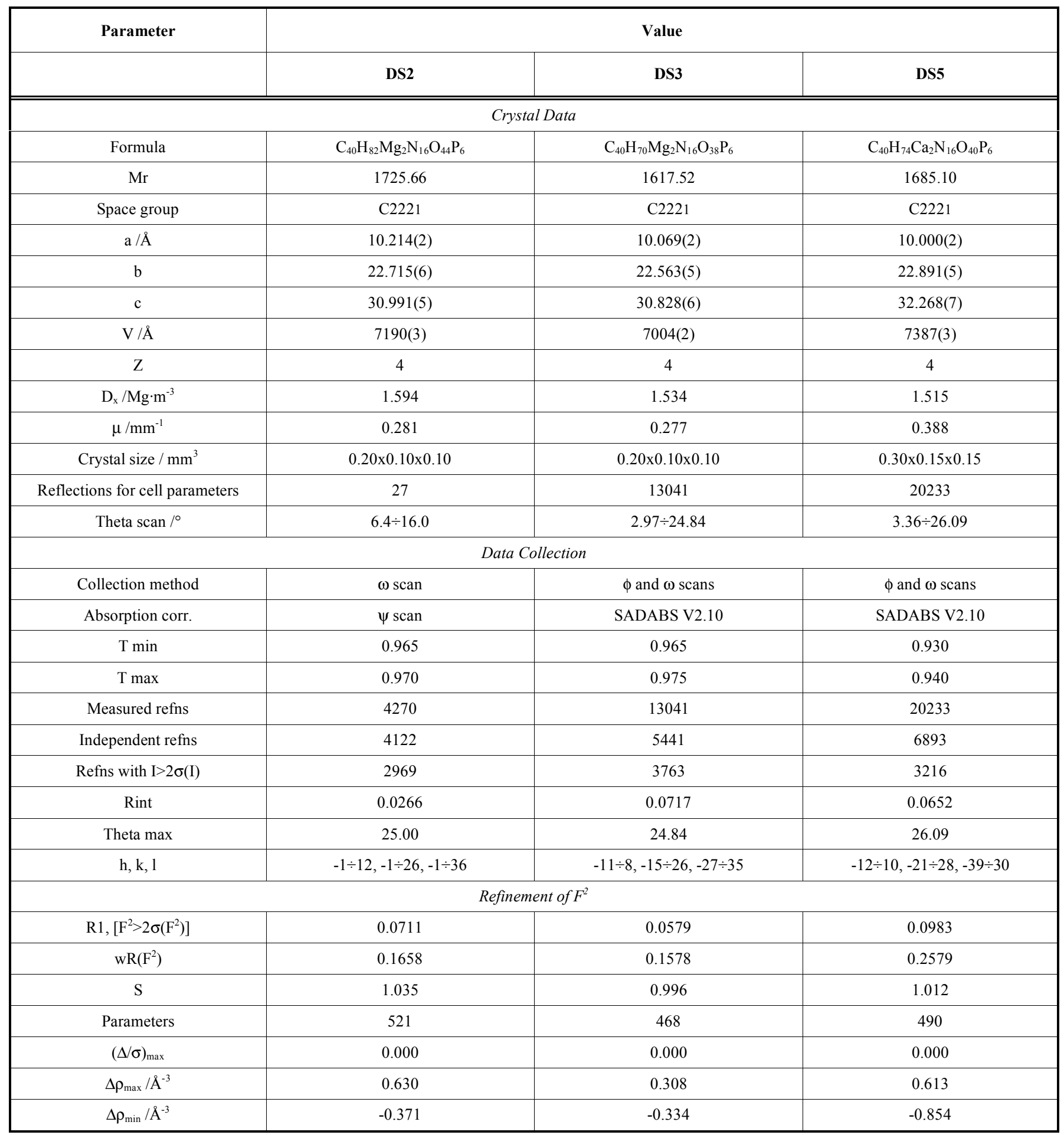

$(120 \pm 2 \mathrm{~K})$, that caused an anisotropic structure alteration, a loss of free water molecules and consequently a failure in collecting suitable data set. On equilibrating the specimen at $295 \pm 2 \mathrm{~K}$ and in the regular room humidity, a back transition took place. The number of co-crystallized water molecules did not reach that found for the freshly prepared crystal. The packing pattern shows hydrophilic layers of water molecules, $\left[\mathrm{Mg}\left(\mathrm{H}_{2} \mathrm{O}\right)_{6}\right]^{2+}$ cations, and Mg-triphosphate moieties parallel to the ab planes (Fig. 1). The free water molecules in the case of the hexa-hydrate isoform (Fig. 1b) have almost the same location as those for the dodeca-hydrate (Fig. 1a); however, the occupancy of most water molecules is much smaller than 1 for hexa-hydrate.

It has to be noted that the $\mathrm{Mg}-\mathrm{O}(\mathrm{P})$ bond lengths from DS2 have the same trend as those for DS1 [13]. In fact the $\mathrm{Mg}-\mathrm{O}(\mathrm{P})$ bond distances are 2.10(2), 2.08(2), 2.01(2), and 2.097(6), 2.076(6), and 2.055(6) $\AA$ for $\alpha, \beta$ and $\gamma$ phosphorus 


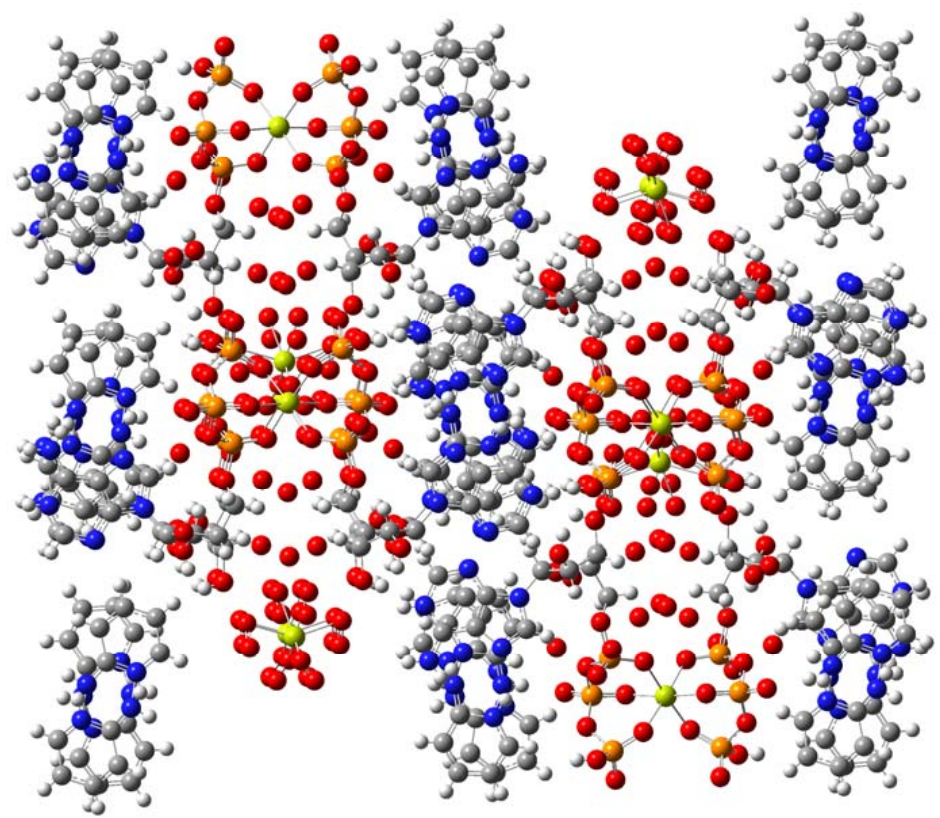

(a)

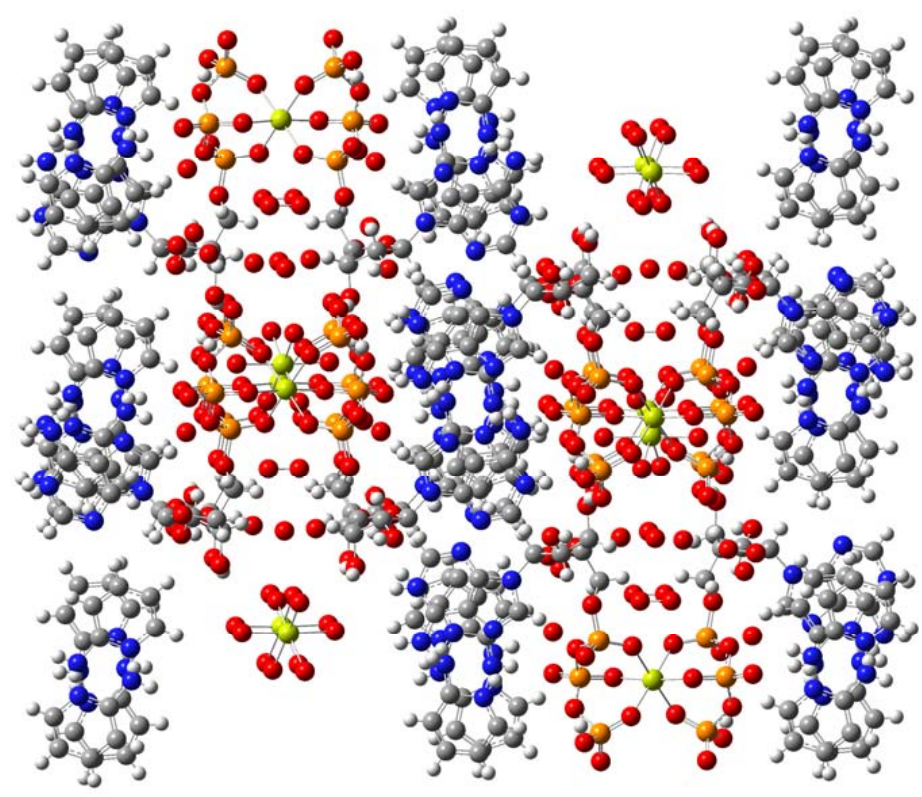

(b)

Fig. (1). Packing diagrams for $\left[\mathrm{Mg}\left(\mathrm{H}_{2} \mathrm{O}\right)_{6}\right] \cdot\left[\mathrm{Mg}(\mathrm{HATP})_{2}\right] \cdot 2(\mathrm{HDPA}) \cdot \mathrm{xH}_{2} \mathrm{O} 1$ as viewed almost along cell axis a for: (a) $\mathrm{x}=12$, data set DS2; (b) $\mathrm{x}=6$, DS3. It has to be noted that the $\left[\mathrm{Mg}\left(\mathrm{H}_{2} \mathrm{O}\right)_{6}\right]^{2+}$ cation is disordered in (a) but not in (b). The occupancy for the free water molecule oxygen atoms for $(\mathrm{b})$ is $1(\mathrm{O} 2 \mathrm{WD}), 0.5(\mathrm{O} 1 \mathrm{WD}$, oxygen on special position), 0.25 (O3WD, O4WD), and 0.5 (O5WD, O6WD); whereas the occupancy for the corresponding water molecule oxygen atoms in (a) are 1, 0.5, 1, 1 (as regard naming of atoms and occupancy value, see the respective CIF files, supplementary material).

atoms for DS1 and DS2, respectively. In the case of DS2, the $\mathrm{Mg}-\mathrm{O}(\mathrm{P} \gamma)$ distance is smaller than the value for $\mathrm{O}(\mathrm{P} \alpha)$ at a probability larger than 99.7 (within $3 \sigma$ ). A similar comment can be done for the structure of the $\left[\mathrm{Mn}\left(\mathrm{H}_{2} \mathrm{O}\right)_{6}\right] \cdot[\mathrm{Mn}$ $\left.(\mathrm{HATP})_{2}\right] \cdot 2(\mathrm{HDPA}) \cdot 12 \mathrm{H}_{2} \mathrm{O}$ derivative reported previously [27]. On the contrary and interestingly, the trend is altered for the model from DS3, where the relation $\mathrm{Mg}-\mathrm{O}(\mathrm{P} \beta)<$ $\mathrm{Mg}-\mathrm{O}(\mathrm{P} \gamma)<\mathrm{Mg}-\mathrm{O}(\mathrm{P} \alpha)$ holds at a probability higher than $99.7 \%$ (see Fig. (2) for the overlay of the structure from DS2 and DS3, and Table 2 ).
The $\mathrm{P} \gamma$-O 7 bond distance confirmed to be the longest in all the structural determinations. The value from DS2 (1.636(7) $\AA$ ) is significantly longer than P $\beta-O 7$ (1.576(7) $\AA$ ) but is close to $\mathrm{P} \alpha-\mathrm{O} 41.627(7) \AA$. As regards DS3 the values for $\mathrm{P} \gamma-\mathrm{O} 7, \mathrm{P} \beta-\mathrm{O} 7$ and $\mathrm{P} \alpha \mathrm{O} 4$ are 1.643(4), 1.597(4) and 1.628(4) $\AA$; thus $\mathrm{P} \gamma-\mathrm{O} 7$ has even a longer value than $\mathrm{P} \beta-\mathrm{O} 4$ at 95.45 probability.

Interestingly, results from refinement of DS3 has also subtle but significant differences with respect to the refinement of the model from DS2 as regards the conformation at 
the triphosphate chain (see Fig. 2), whereas the ribose system is almost unaltered. These effects can be related to the differences in the co-crystallized water molecules that reside mostly in the proximity of the phosphate systems. In fact, the ribose conformation is still $\mathrm{C} 2$ '-endo/C3'-exo upon reducing the overall number of free water molecules (Table 3). The most important hydrogen bonds that involve the ribose system are equivalent for the two models. The ribose $\mathrm{O} 2$ ' and $\mathrm{O}^{\prime}$ ' oxygen atoms are involved in strong $\mathrm{H}$-bonds to $\mathrm{O} 10(\gamma$-phosphate) $(\mathrm{O} 2$ '...O10 and $\mathrm{O} 3$ '...O10, 2.971(9) and 2.639(8) $\AA$ ), and to a free water molecule (O2'...O6WD (SOF 1), 2.836(8) $\AA$ ) for DS2. The corresponding pattern for the structure from DS3 is the following: O2'...O10 and O3'...O10, 2.756(5) and 2.717(5) $\AA$, and $\mathrm{O} 2$ '...O5WD (SOF 0.5), 2.869(5) $\AA$. The $\alpha$-phosphate for the model from DS2 has a strong H-bond with a free water molecule: O2...O3WD (SOF 1), 2.666(8) A; such a strong H-bond does not occur from the DS3 data set, the shortest contact of that type being 3.279(6) $\AA$ to O2WD (SOF 1). The $\beta$ phosphate, through $\mathrm{O} 5$, has strong $\mathrm{H}$-bond $(\mathrm{O} \ldots \mathrm{O}, 2.664(8)$ $\AA$ ) to O7WD (SOF 1) from DS2, but in the case of model from DS3 the corresponding contact distance (to O2WD) is 3.065(6) A. As regards the $\gamma$-phosphate for models from DS2 and DS3, O8 has $\mathrm{H}$-bond with $\mathrm{H}-\mathrm{N} 1$ function of adenine with almost equal donor...acceptor distances: 2.529(8) and 2.532(5) $\AA$. O $10(\mathrm{P} \gamma)$ has strong H-bonds to a free water molecule with donor...acceptor distances: 2.653(9) (DS2, O2WD SOF 0.5) and 2.827(6) $\AA$ (DS3, O1WD SOF 0.5).
The position of the $\left[\mathrm{Mg}\left(\mathrm{H}_{2} \mathrm{O}\right)_{6}\right]^{2+}$ cation is influenced by the free water molecules; in fact, the (HATP) $\mathrm{Mg} \ldots \mathrm{Mg}\left(\mathrm{OH}_{2}\right)$ shortest intermetallic distance is 5.361(10) and 5.116(7) $\AA$ for DS2 and DS3, respectively. In other words, on reducing the hydration of the crystal, the hexa-aqua magnesium cation approaches to the $\mathrm{Mg}(\mathrm{HATP})_{2}{ }^{4-}$ grouping.

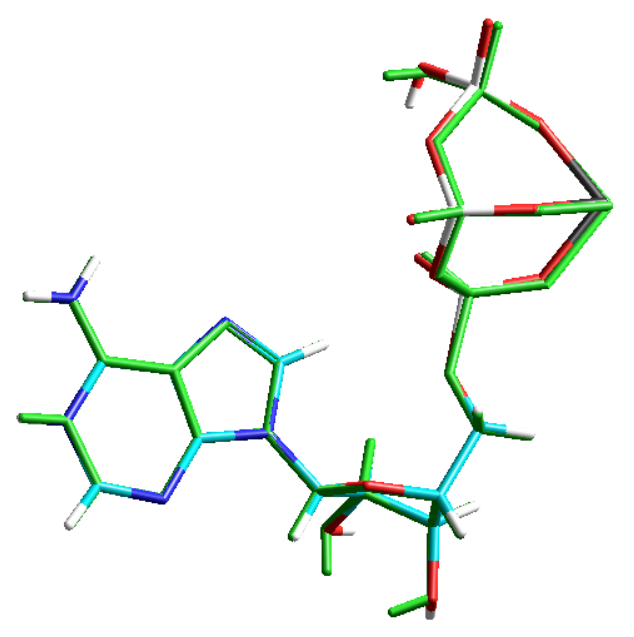

Fig. (2). Overlay for the $\mathrm{Mg}(\mathrm{HATP})^{-}$moiety of $\left[\mathrm{Mg}\left(\mathrm{H}_{2} \mathrm{O}\right)_{6}\right]$. $\left[\mathrm{Mg}(\mathrm{HATP})_{2}\right] \cdot 2(\mathrm{HDPA}) \cdot \mathrm{xH}_{2} \mathrm{O}$ 1: monochrome green relevant to $\mathrm{x}$ $=12$, DS2; color relevant to $\mathrm{x}=6, \mathrm{DS} 3$.

Table 2. The Selected Bond Distances and Angles for the Structures of $\left[\mathrm{Mg}\left(\mathrm{H}_{2} \mathrm{O}\right)_{6}\right] \cdot\left[\operatorname{Mg}(\mathrm{HATP})_{2}\right] \cdot 2(\mathrm{HDPA}) \cdot \mathrm{HH}_{2} \mathrm{O}, 1$

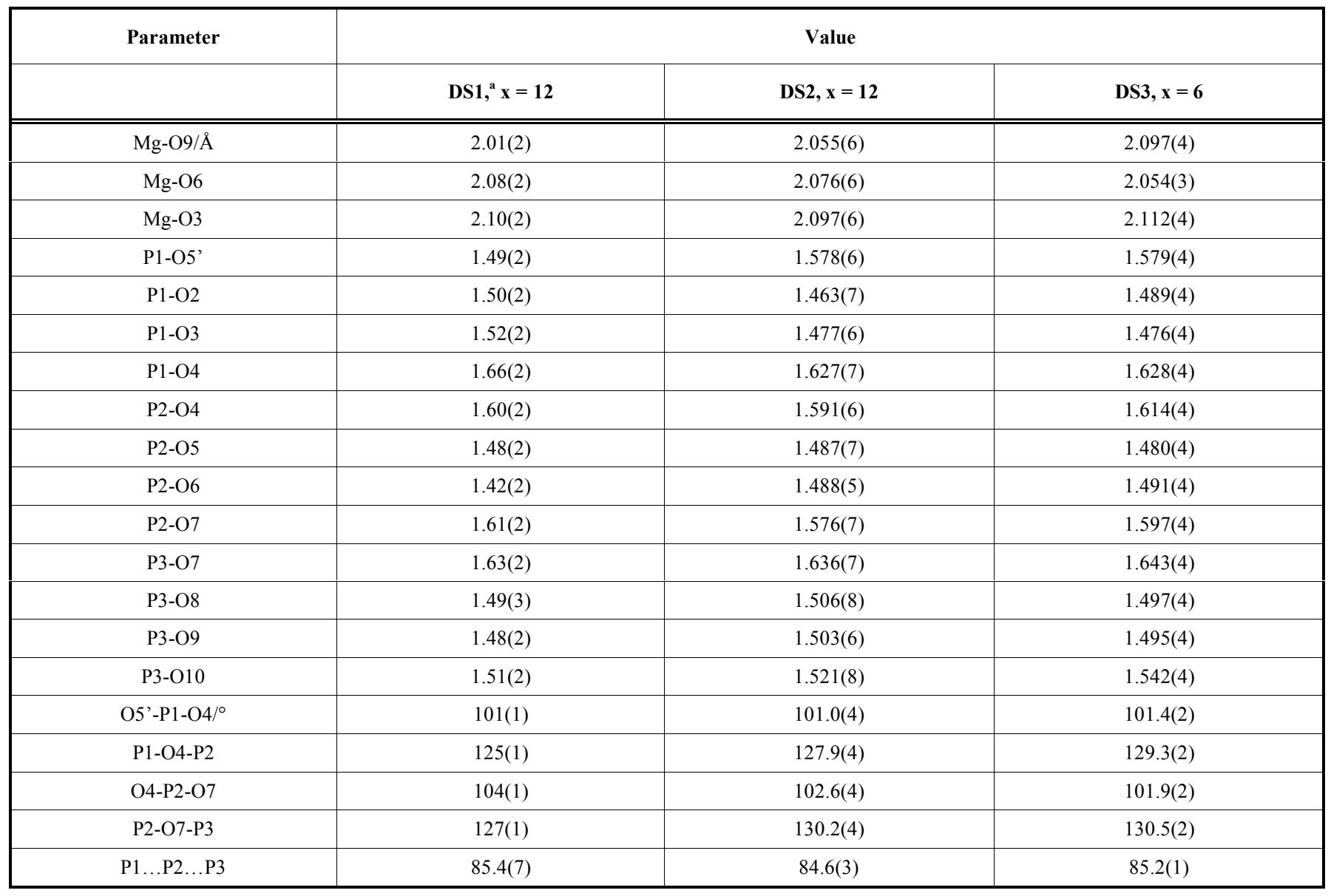

\footnotetext{
${ }^{\text {a }}$ Previous work, see Ref [13].
} 
Table 3. The Selected Torsion Angles for the Structures of $\left[\mathrm{Mg}\left(\mathrm{H}_{2} \mathrm{O}\right)_{6}\right] \cdot\left[\mathrm{Mg}(\mathrm{HATP})_{2}\right] \cdot 2(\mathrm{HDPA}) \cdot \mathrm{xH}_{2} \mathrm{O}, 1$

\begin{tabular}{|c|c|c|c|}
\hline & DS1, ${ }^{a} x=12$ & DS2, $x=12$ & DS3, $x=6$ \\
\hline$\chi\left(\mathrm{C} 8-\mathrm{N} 9-\mathrm{C} 1^{\prime}-\mathrm{O} 1^{\prime}\right){ }^{\circ}$ & $67(1.2)$ & $68.2(4)$ & $67.8(2)$ \\
\hline$\tau_{0}\left(\mathrm{C} 4^{\prime}-\mathrm{O} 1^{\prime}-\mathrm{C} 1^{\prime}-\mathrm{C} 2^{\prime}\right)$ & $-10(1.2)$ & $-10.1(5)$ & $-10.4(2)$ \\
\hline$\tau_{2}\left(\mathrm{C} 1{ }^{\prime}-\mathrm{C} 2^{\prime}-\mathrm{C} 3^{\prime}-\mathrm{C} 4{ }^{\prime}\right)$ & $-31(1.2)$ & $-32.8(5)$ & $-32.3(2)$ \\
\hline$\tau_{3}\left(\mathrm{C} 2^{\prime}-\mathrm{C} 3^{\prime}-\mathrm{C} 4^{\prime}-\mathrm{O} 1^{\prime}\right)$ & $25(1.2)$ & $27.3(5)$ & $27.6(2)$ \\
\hline$\tau_{4}\left(\mathrm{C} 3{ }^{\prime}-\mathrm{C} 4{ }^{\prime}-\mathrm{O} 11^{\prime}-\mathrm{C} 1{ }^{\prime}\right)$ & $-9(1.2)$ & $-11.3(5)$ & $-11.2(2)$ \\
\hline$\psi_{\mathrm{OC}}\left(\mathrm{C} 3^{\prime}-\mathrm{C} 4^{\prime}-\mathrm{C} 5^{\prime}-\mathrm{O} 5^{\prime}\right)$ & $57(1.2)$ & $55.7(5)$ & $54.8(2)$ \\
\hline$\phi\left(\mathrm{C} 4{ }^{\prime}-\mathrm{C}^{\prime}{ }^{\prime}-\mathrm{O} 5\right.$ '- $\left.\mathrm{P} \alpha\right)$ & $168(1)$ & $169.3(4)$ & $165.9(1)$ \\
\hline$\omega_{1}\left(\mathrm{C}^{\prime}-\mathrm{O} 5^{\prime}-\mathrm{P} \alpha-\mathrm{O} \alpha \beta\right)$ & $-66(1)$ & $-66.6(3)$ & $-62.6(1)$ \\
\hline$\omega_{2}\left(\mathrm{O} 5^{\prime}-\mathrm{P} \alpha-\mathrm{O} \alpha \beta-\mathrm{P} \beta\right)$ & $159(1)$ & 157.1(2) & 155.3(1) \\
\hline$\omega_{3}(\mathrm{P} \alpha-\mathrm{O} \alpha \beta-\mathrm{P} \beta-\mathrm{O} \beta \gamma)$ & $67(1)$ & $67.5(2)$ & $65.3(1)$ \\
\hline$\omega_{4}(\mathrm{O} \alpha \beta-\mathrm{P} \beta-\mathrm{O} \beta \gamma-\mathrm{P} \gamma)$ & $-101(1)$ & $-97.8(2)$ & $-100.3(1)$ \\
\hline $\mathrm{P}^{\mathrm{b}}$ & $178(1)$ & $179.4(4)$ & $179.0(2)$ \\
\hline
\end{tabular}

${ }^{a}$ Previous work, see Ref [13].

${ }^{\mathrm{b}} \mathrm{P}$ is the pseudo-rotation phase angle, see Ref [9].

The structure for $\left[\mathrm{Ca}\left(\mathrm{H}_{2} \mathrm{O}\right)_{6}\right] \cdot\left[\mathrm{Ca}(\mathrm{HATP})_{2}\right] \cdot 2(\mathrm{HDPA})$. $8 \mathrm{H}_{2} \mathrm{O}$ from data set DS5 has a water molecule less than that previously obtained from DS4 [13]. The accuracy for the present analysis is significantly improved on the basis of conventional agreement factors and of esds for geometrical parameters (Table 4). The small change of the overall number of free water molecules can be probably related to differences in the humidity of the two laboratories in which DS4 and DS5 were collected [10]. In fact, the $\mathrm{Ca}-\mathrm{O}(\mathrm{P})$ bond distance trend, the conformation of triphosphate moiety do not change significantly (the values are equal within $2 \sigma$ ) (see Table 4). The shortest contact distances between the calcium ion linked to triphosphate and the calcium center from hexaaqua cation are very close in the models refined from the two data sets: 5.43(1) $\AA$ (DS4) and 5.41(1) $\AA$ (DS5). Interestingly, the torsion angles on the backbone atoms from triphosphate from the two models are equal within $1 \sigma$, excluding the $\mathrm{C}^{\prime}-\mathrm{O} 5{ }^{\prime}-\mathrm{P} \alpha-\mathrm{O} \alpha \beta$ angle whose values are $-58(2)^{\circ}$ and $-65.0(7)^{\circ}$ from DS4 and DS5. Significant changes are evident from the comparison of ribose ring conformations (C2'-endo with small component of $\mathrm{C} 1^{\prime}$ 'exo, pseudorotation phase angle $\mathrm{P}=156(2)^{\circ}$, DS4, and $\mathrm{C} 2$ '-endo/C3'-exo, $\mathrm{P}=$ $177.8(6)^{\circ}$, DS5) and conformations around the glycosidic bond (C8-N9-C1'-O1', $\chi, 58(2)^{\circ}$ DS4 and 67.7(6) ${ }^{\circ}$ DS5). In fact, a water molecule is close to $\mathrm{O} 2(\mathrm{P} \alpha)$ atom from DS4 but not in the model from DS5. Instead, the location of water molecules proximal to $\mathrm{P} \beta$ - and $\mathrm{P} \gamma$-phosphate oxygen atoms is mostly the same in the two models.

\section{Other Structures of Nucleoside-tri(di)Phosphates from Literature}

The work by Bianchi et al. [28] reports on the structure of an adduct between a polyfunctional macrocyclic ligand, consisting of two terpyridine moieties linked together by two diamine chains and tymidine 5'-triphosphate TTP (Scheme 1). The triphosphate chain is more extended (P...P...P angle is $\left.97.0(6)^{\circ}\right)$ than that for the $\left[\mathrm{M}(\mathrm{HATP})_{2}\right]^{4-}$ series probably owing to the electrostatic repulsions between the negative charges on the $\mathrm{O}(\mathrm{P})$ atoms, that is not attenuated by any $\mathrm{M}-$ $\mathrm{O}(\mathrm{P})$ bonds. The O-P bridging bond distances are: 1.604(4), 1.602(4), 1.616(4), 1.585(4), 1.640(4) $\AA$, for $\mathrm{P} \alpha-\mathrm{O} 5$ ', $\mathrm{P} \alpha-$ $\mathrm{O} \alpha \beta, \mathrm{P} \beta-\mathrm{O} \alpha \beta, \mathrm{P} \beta-\mathrm{O} \beta \gamma, \mathrm{P} \gamma-\mathrm{O} \beta \gamma$, respectively. A strict closeness to the corresponding values for structure of 1 (DS3) and 2 (DS5), especially as regards the $\beta$ - and $\gamma$-phosphate region is evident.

The work by Kato et al. [29] reports on the structure of $\left[\mathrm{Cu}_{4}(\mu-\mathrm{ATP})_{2}(\mathrm{BPY})_{4}\right](\mathrm{BPY}=2,2$ '-bipyridyl $)$ where the two ATP molecules have the phosphate groups tightly linked to $\mathrm{Cu}(\mathrm{II})$ atoms, and have bridging $\mathrm{P} \alpha-\mathrm{O} 5, \mathrm{P} \alpha-\mathrm{O} \alpha \beta, \mathrm{P} \beta-$ $\mathrm{O} \alpha \beta, \mathrm{P} \beta-\mathrm{O} \beta \gamma, \quad \mathrm{P} \gamma-\mathrm{O} \beta \gamma$ bond distances 1.582(4), 1.592(4), $1.611(5), 1.583(3), 1.644(3) \AA$ (namely ATP1) and 1.580(4), $1.600(4), 1.602(5), 1.577(4), 1.637(4) \AA$ (namely ATP2). It is clear that all the corresponding values are equal within $2 \sigma$, and are equal within $3 \sigma$ to those from the work on TTP by Bianchi et al. [28], even though the chemical environment for the triphosphate chain is different in the two structures. The absence of significant discrepancies between terminal P- 
Table 4. The Selected Bond Distances and Angles for the Structures of $\left[\mathrm{Ca}\left(\mathrm{H}_{2} \mathrm{O}\right)_{6}\right] \cdot\left[\mathrm{Ca}(\mathrm{HATP})_{2}\right] \cdot 2\left(\mathrm{HDPA}_{2} \cdot \mathrm{xH}_{2} \mathrm{O}, 2\right.$

\begin{tabular}{|c|c|c|}
\hline \multirow[t]{2}{*}{ Parameter } & \multicolumn{2}{|c|}{ Value } \\
\hline & DS4,${ }^{\mathrm{a}} \mathrm{x}=9$ & DS5, $x=8$ \\
\hline $\mathrm{Ca} 1-\mathrm{O} 3 / \AA ̊$ & $2.28(3)$ & $2.298(8)$ \\
\hline Ca1-O6 & $2.30(2)$ & $2.346(7)$ \\
\hline O5'-P1 & $1.50(3)$ & $1.594(8)$ \\
\hline $\mathrm{P} 1-\mathrm{O} 4$ & $1.64(3)$ & $1.562(11)$ \\
\hline O4-P2 & $1.54(3)$ & $1.594(8)$ \\
\hline P2-O7 & $1.57(2)$ & $1.558(7)$ \\
\hline P1-O4-P2 & 131(2) & $132.2(5)$ \\
\hline $\mathrm{O} 4-\mathrm{P} 2-\mathrm{O} 7$ & $108(1)$ & $104.6(5)$ \\
\hline P2-O7-P3 & $132(1)$ & $132.0(4)$ \\
\hline $\mathrm{P} 1 \ldots \mathrm{P} 2 \ldots \mathrm{P} 3$ & $87.5(9)$ & $87.4(4)$ \\
\hline
\end{tabular}

${ }^{a}$ Previous work, see Ref [13].

Ot and $\mathrm{P}-\mathrm{O}(\mathrm{M})$ bonds distances in the selected structures show that metal coordination does not have much influence on nature of P-Ot bonds.

The structure of $\left[\mathrm{Cu}(\mathrm{TERPY})\left(\mathrm{H}_{2} \mathrm{O}\right)_{2}\right][\mathrm{Cu}(\mathrm{TERPY})$ $(\mathrm{ADP})]\left(\mathrm{H}_{2} \mathrm{ADP}\right) \cdot 16 \mathrm{H}_{2} \mathrm{O}, \mathrm{ADP}=$ adenosine 5'-diphosphate, TERPY = 2,2':2"-terpyridine [30] confirms that diphosphate chain has terminal $\mathrm{P} \alpha-\mathrm{O}$ and $\mathrm{P} \beta-\mathrm{O}$, and $(\mathrm{Cu}) \mathrm{O}-\mathrm{P}$ bond lengths that agree with the finding presented above for NTPs that P-Ot lengths do not vary significantly upon complex formation to $\mathrm{Cu}$ (II) (and to other divalent cations from alkaline earth group and first row block-d of the periodic table). On the other hands, in case an oxygen atom from phosphate groups is protonated the relevant $\mathrm{O}-\mathrm{P}$ bond distance is significantly elongated with respect to the not protonated ones.

Therefore, the structural data commented in this work show that the (di)triphosphate backbone is not much influenced, at least as regards terminal P-Ot bond distances, by metal ligation to phosphate oxygen atoms, or by interaction with water molecules or receptor molecules, that mimic enzymes. Even the bridging $\mathrm{P}-\mathrm{O}(\mathrm{P} / \mathrm{C})$ bond lengths seems to be not much altered through metal coordination or interaction with amines at least in the model complexes so far analyzed. Instead, the orientation of the triphosphate system and the conformation around the glycosidic bond and that of ribose ring are significantly influenced by those factors.

\section{The Selected Computational Data from Literature}

The results reported above from experimental determinations are compared to results from computations through the density functional (DFT) methods at the Becke3LYP/(6$31+\mathrm{G}^{* *}$ ) level reported on models for ATP and Mg-ATP molecules [11]. The models consisted of methyltriphosphate, $\left(\mathrm{CH}_{3} \mathrm{OPO}_{2}\right) \mathrm{O}\left(\mathrm{PO}_{3}\right)_{2}{ }^{4-}$ and its $\mathrm{Mg}(\mathrm{II})$ complexes. The structure optimization showed that $\mathrm{Mg}$ is tricoordinate by the three phosphate groups. The computed $\mathrm{Mg}-\mathrm{O}(\mathrm{P} \gamma)$ length is the shortest $\mathrm{Mg}-\mathrm{O}(\mathrm{P})$ bond distance in the molecule, in agreement with the structural determinations for 1. The work shows that the P $\gamma-\mathrm{O} \beta \gamma$ bond length is elongated by $0.135 \AA$ upon metal coordination, an effect larger than other computed elongations for the P-O bridging bonds. On the contrary, the computed $\mathrm{P} \beta-\mathrm{O} \alpha \beta$ and $\mathrm{P} \alpha-\mathrm{O} 5$ ' bond distances undergo a shortening by 0.092 and $0.084 \AA$, respectively upon ligation of $\mathrm{Mg}(\mathrm{II})$ cation to methyltriphosphate in $\left\{\mathrm{Mg}\left(\mathrm{CH}_{3} \mathrm{OPO}_{2}\right) \mathrm{O}\left(\mathrm{PO}_{3}\right)_{2}\right\}^{2-}$. The authors relate the large lengthening effect computed for the $\mathrm{P} \gamma-\mathrm{O} \beta \gamma$ bond to the bond breakages that occur in many enzymatic hydrolytic reactions.

Similar computations were reported previously for $\mathrm{Ca}(\mathrm{II})$-methyltriphosphate species, by using the level of theory DFT-Becke3LYP/(Lanl2DZ, Ca; 6-31G, CHO; 6$\left.31 \mathrm{G}^{* *}, \mathrm{P}\right)$ [31]. The $\mathrm{Ca}-\mathrm{O}(\mathrm{P})$ computed bond distances are $2.525,2.338$ and $2.228 \AA$ for $\alpha$-, $\beta$ - and $\gamma$-phosphate, respectively, showing that the strongest interaction of the metal cations is that to the terminal $\mathrm{PO}_{3}$ grouping. The computed $\mathrm{P} \gamma$-O $\beta \gamma$ bond distance for the model undergoes a lengthening by $0.090 \AA$ upon ligation to $\mathrm{Ca}(\mathrm{II})$, much smaller than the corresponding one computed for the Mg-model. The computed P-O-P bond angles are 139.8 and $145.8^{\circ}$, for P-O $\alpha \beta-\mathrm{P}$ and $\mathrm{P}-\mathrm{O} \beta \gamma-\mathrm{P}$ respectively, and show a narrowing of 9.9 and $6.9^{\circ}$ respectively. In conclusion the computed values for bond distances and angles have trends that agree well with experiments for metal-nucleotide complexes, at least for $\mathrm{Mg}(\mathrm{II}) / \mathrm{Ca}(\mathrm{II})$-triphosphate species. 


\section{The Selected Structural Studies for Protein Systems from Literature}

\section{Structures that have at Least Two Divalent Metal Atoms in the Proximity of the Phosphate Backbone}

As compounds $\mathbf{1}$ and $\mathbf{2}$ have two metal centers in the proximity of the triphosphate chain we looked for similar complexes in the PDB [3]. The selection was usually based on small values for the nominal resolution and on how recent was the deposition in the data bank. A paper relevant to the structural analysis of the active site of $N^{5}$-Carboxyaminoimidazole Ribonucleotide Synthetase from Escherichia coli is first commented (see Ref 32 and PDB structure code 3 ETH Ref [3]). The crystals contain a dimer per asymmetric unit and the X-ray data had a nominal resolution of $1.6 \AA$. The enzyme is required for purine biosynthesis in microbes, contains two ATP molecules linked to magnesium ions and is postulated to hydrolyze the $\gamma$-phosphoryl group and form a carboxy-phosphate intermediate, that in turn transfers $\mathrm{CO}_{2}$ onto 5-amino-imidazole ribonucleotide (AIR) to bring about 5-aminocarboxy-imidazole ribonucleotide ( $\mathrm{N}^{5}$-CAIR). The first step in the sequence is therefore the attack of hydrogen carbonate anion on $\mathrm{P} \gamma$. The phosphate group of each nucleotide have different binding patterns to the metals (Fig. 3). One of the metal ions per each Mg-ATP system links two phosphate groups ( $\alpha$ and $\beta$ ). Interestingly, a second metal cation interacts with just the $\beta$ - and $\gamma$-phosphate groups for each nucleotide. The phosphate chains are relatively extended, the P...P...P bond angles being 106 and $108^{\circ}$. The (P)O-P bridging distances (mean values for corresponding bonds from the two nucleotide molecules) are in the range 1.569-1.603 $\AA$, the largest value being relevant to a $\mathrm{P} \gamma-\mathrm{O} \beta \gamma$ bond. It has to be noted that the structure for $\mathbf{1}$ has significant similarities to that of the enzyme system structure. In fact, the presence of two proximal $\mathrm{Mg}$ (II) ions in $\mathbf{1}$ reminds that for 3ETH. Water molecules play some roles in the coordination to the metals both for 1 and $3 \mathrm{ETH}$ and some water molecules form $\mathrm{H}$-bonds with the phosphate groups. The elongation for $\mathrm{P} \gamma-\mathrm{O} \beta \gamma$ bridging bond distances in $\mathbf{1}$ when compared to the other $\mathrm{P}-\mathrm{O}$ vectors is reminiscent of the finding from $3 \mathrm{ETH}$ structure. On the other hand, there are also significant differences between 1 and 3ETH: (a) both the metal centers have some phosphate oxygen atoms in the first coordination sphere for the enzyme system, whereas one of the metal is linked to two triphosphate chains from two ATPs and the second one is linked to six water molecules for 1; (b) the shortest $\mathrm{Mg} . . . \mathrm{Mg}$ distances are significantly different (5.116(4) $\AA$ for 1 and $3.74 \AA$ (average) for $3 E T H)$; (c) the metal ions are linked to aminoacids residues for $3 \mathrm{ETH}$, whereas no interaction between metal and DPA ligand exists for 1 ; (d) the conformation of the ribose ring is $\mathrm{C} 3$ '-endo for 3ETH, whereas is $\mathrm{C}^{2}$ '-endo/C3'-exo for $\mathbf{1}$.

The adenylyl cyclases catalyze the conversion of ATP to cAMP (3'-5'-cyclic adenosine monophosphate) and pyrophosphate (see Ref 33 and PDB structure code 3C16 Ref [3]). The enzymatic process requires $\mathrm{Mg}(\mathrm{II})$ or $\mathrm{Mn}(\mathrm{II})$ as cofactor. Some isoforms of the enzyme are stimulated by $\mathrm{Ca}(\mathrm{II})$ ions whereas some others are inhibited. A series of crystal structures determinations have been done and reported in the paper by Mou et al. [33] including the systems $\mathrm{Ca}(\mathrm{II})$-ATP-enzyme that was solved at a nominal resolution of $2.9 \AA$. Even though this latter value is high the structure seemed worthy of attention because the presence of two metal centers located near the triphosphate chain. The work elucidates the mode of calcium binding to ATP. The $\beta$ - and $\gamma$-phosphate group of an ATP molecule interact tightly with $\mathrm{Mg}(\mathrm{II})$ whereas all three phosphate groups of a second molecule of ATP interact with $\mathrm{Ca}$ (II) ions that sit in two close positions (contact distance $2.786 \AA$ ). It has to be noted that the ionic radius for $\mathrm{Ca}$ (II) is $1.14 \AA$ [34]. This is an unusual location for a couple of divalent metal ions and the authors thought that this might be in part due to the presence of static disorder for the metal ions. It is possible that other explanations can stem also from stabilizing interactions that occur between the metal ions and the ligands, including water molecules, aminoacid residues and triphosphate chain. In

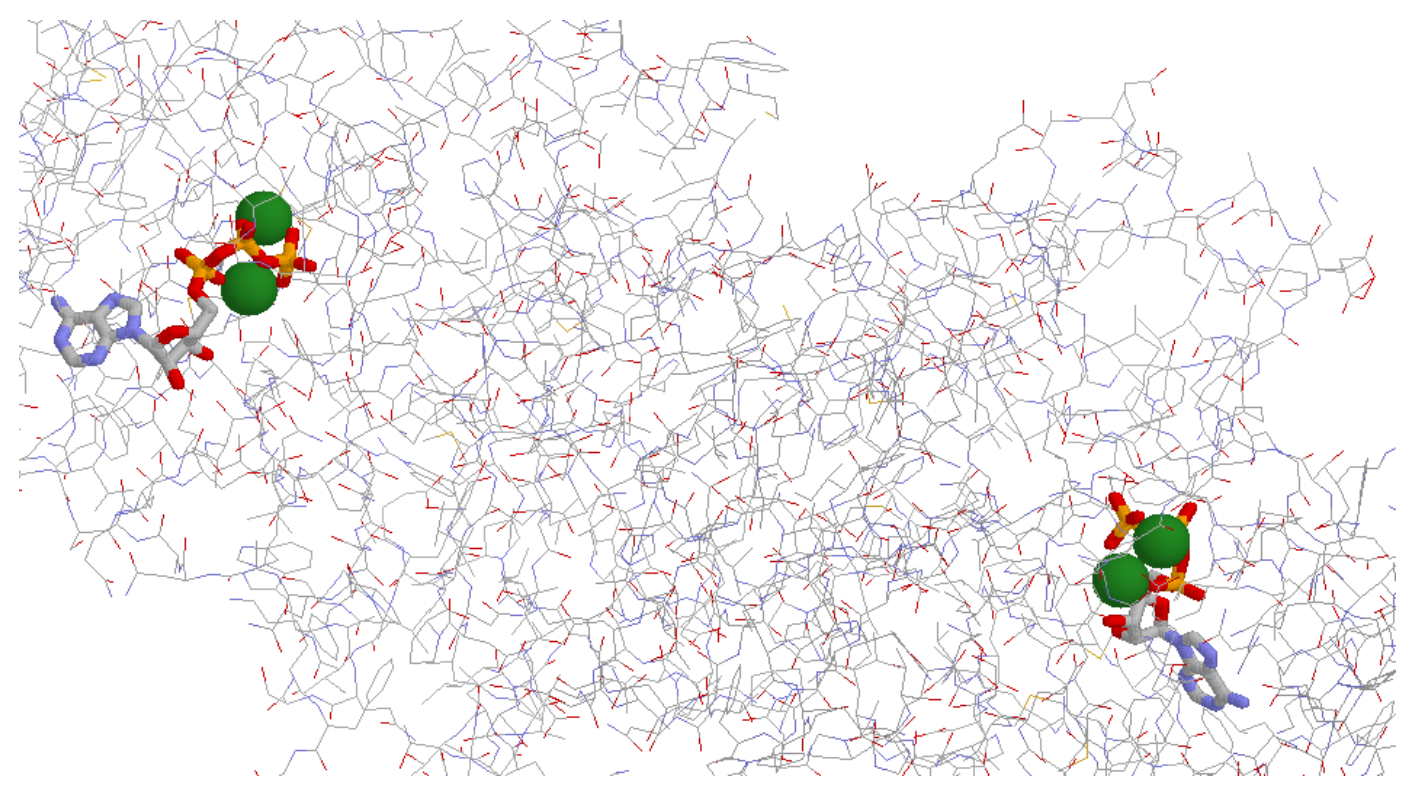

Fig. (3). The diagram shows two sites of $N^{5}$-Carboxyaminoimidazole Ribonucleotide Synthetase from Escherichia coli (see Ref [32] and PDB structure code 3ETH Ref [3]). The ATP molecules are represented color tube style whereas the $\mathrm{Mg}(\mathrm{II})$ cations are depicted as green balls. 
fact, this latter group has linking interactions to metal ions via $\mathrm{O}(\mathrm{P} \alpha)(2.638 \AA) \mathrm{Ca} 1$, and via $\mathrm{O}(\mathrm{P} \beta)(2.108 \AA) \mathrm{Ca} 2$. The bridging P-O bond distances range 1.623-1.663 $\AA$, the largest value being relevant to $\mathrm{P} \beta-\mathrm{O} \alpha \beta$, that is in agreement with hydrolytic formation of pyrophosphate.

\section{Structures that have a Metal Atom in the Proximity of the Phosphate Backbone}

The work by Regni et al. (see Ref [35] and PDB structure code $3 \mathrm{H} 5 \mathrm{~N}$, Ref [3]) reports on the crystal structures of EScherichia Coli MccB enzyme that catalyzes a modification of a heptapeptide (MccA) during the biosynthesis of the antibiotic microcin C7 (MccC7). The MccB-Mg-ATP system has four $\mathrm{Mg}$ (II) and four Zinc(II) ions in addition to four ATP molecules as substrate in the asymmetric unit (Fig. 4). The nominal resolution was $1.90 \AA$. The $\mathrm{Zn}(\mathrm{II})$ ions are far away from the nucleotide and just $\mathrm{Mg}(\mathrm{II})$ ions are in the proximity of the triphosphate chain in all the molecules and all the three phosphate groups of each chain are involved in interactions to the metal. The $\mathrm{Mg}-\mathrm{O}(\mathrm{P})$ bond distances span the wide range 1.948-2.546 $\AA$. For a molecule, namely ATP1, the shortest $\mathrm{Mg}-\mathrm{O}(\mathrm{P})$ bond distances is at $\alpha$ phosphate (1.948 $\AA$ ); in another molecule, namely ATP2, the shortest $\mathrm{Mg}-\mathrm{O}(\mathrm{P})$ linkage is at $\beta$-phosphate (2.012 $\AA$ ). ATP1 and ATP2 have a hexacoordinate sphere (pseudo-octahedral) in which three positions are occupied by water molecules. The structure for the ATP3 molecule shows the $\mathrm{Mg}$ (II) ion linked just to phosphate oxygen atoms (and not to water ligands). Finally, the structure for ATP4 molecule shows the $\mathrm{Mg}$ (II) linked to the three phosphates groups and to two water molecules. The longest P-O bridging distance is $\mathrm{P}(\gamma)$ $\mathrm{O}(\beta \gamma)$ for ATP1 (1.625 $\AA)$. On selecting ATP2 the bridging $\mathrm{P}-\mathrm{O}$ bond distances span 1.600-1.615 $\AA$ and the largest value is relevant to $\mathrm{P} \alpha-\mathrm{O} 5$ '. The triphosphate chains for the four ATPs are relatively extended, the P...P...P angles being in the range $99-103^{\circ}$.

The work by Evans et al. (see Ref 36 and PDB structure code 3F2B, ref [3]) reports on the X-ray structural determination at $2.4 \AA$ nominal resolution for a polymerase enzyme (that is responsible for the genome duplication Gram-positive bacteria Geobacillus kaustophilus) in ternary complex with DNA and dGTP (2'-deoxy guanosine 5'triphosphate). The structure was selected because it contains a NTP different from ATP. The active site, that contains the MgGTP system, has a $\mathrm{Mg}(\mathrm{II})$ ion linked to $\mathrm{P} \alpha, \mathrm{P} \beta$ and $\mathrm{P} \gamma$ with $\mathrm{Mg}-\mathrm{O}$ distances $1.860,1.966$ and $2.176 \AA$, respectively. Thus the strongest interaction of the metal is at P $\alpha$. The coordination sphere around the metal cation has six sites that include also a water molecule and two oxygen atoms from aspartate residues. The triphosphate chain is somewhat more extended than in 1: P...P...P angle being $97.3^{\circ}$. The bridging $\mathrm{P} \alpha-\mathrm{O} 5$ ', $\mathrm{P} \alpha-\mathrm{O} \alpha \beta, \mathrm{P} \beta-\mathrm{O} \alpha \beta, \mathrm{P} \beta-\mathrm{O} \beta \gamma$ and $\mathrm{P} \gamma-\mathrm{O} \beta \gamma$ distances are $1.621,1.626,1.611,1.612,1.598 \AA$. Terminal P-O bond distances are, $1.499(\mathrm{P} \alpha), 1.495(\mathrm{P} \beta)$, and 1.488 and $1.521 \AA$ $(\mathrm{P} \gamma)$, whereas $\mathrm{P}-\mathrm{O}(\mathrm{Mg})$ bond distances are, $1.500(\mathrm{P} \alpha), 1.502$ $(\mathrm{P} \beta)$ and $1.515 \AA(\mathrm{P} \gamma)$.

The work by Jönsson et al. (see Ref [37] and PDB structure code 3 CYI, Ref 3 ) reports on the X-ray structural analysis of sulfiredoxin a Mg-ATP enzyme that catalyzes a novel enzymatic reaction: the reduction of cysteinic sulfinic acid Cys- $\mathrm{SO}_{2}{ }^{-}$. The nominal resolution for the structure was 1.8 $\AA$. The metal ion is linked to $\mathrm{P} \alpha, \mathrm{P} \beta$ and $\mathrm{P} \gamma$ with $\mathrm{Mg}-\mathrm{O}(\mathrm{P})$ distances 2.142, 2.076 and $2.180 \AA$, respectively. The triphosphate chain is in the extended form: P...P...P angle $102^{\circ}$. The P-O bridging distances are: 1.609 ( $\left.\mathrm{P} \alpha-\mathrm{O} 5^{\prime}\right), 1.619$

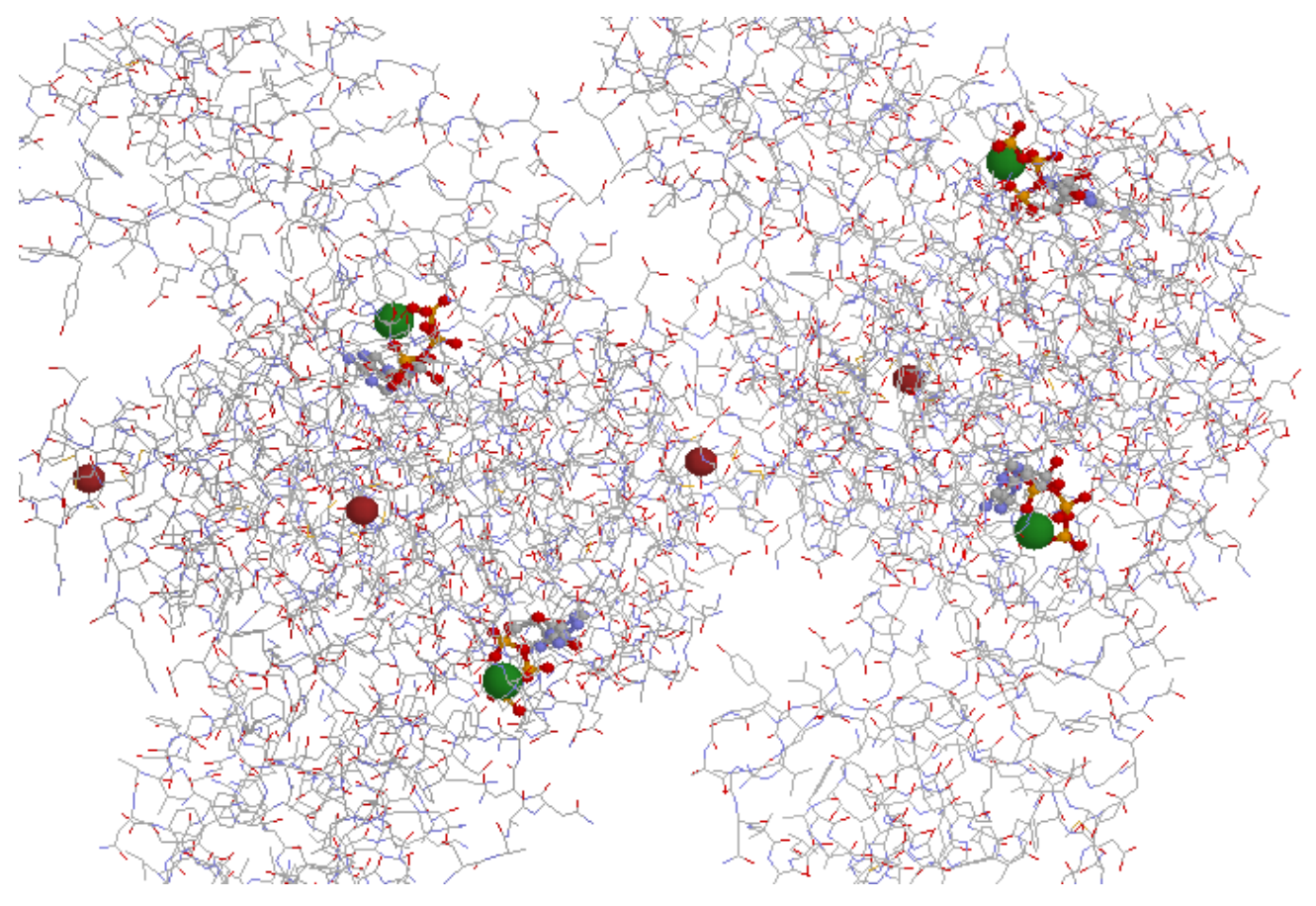

Fig. (4). The diagram shows details of the crystal structures of Escherichia Coli MccB enzyme that catalyzes a modification of a heptapeptide (MccA) during the biosynthesis of the antibiotic microcin C7 (MccC7) (see Ref [35] and PDB structure code 3H5N, Ref [3]). The MccB-Mg-ATP system has four Mg(II) and four Zinc(II) ions in addition to four ATP molecules in the asymmetric unit. The ATP molecules are depicted color ball \& stick style, the $\mathrm{Mg}(\mathrm{II})$ ions are dark green balls, whereas the $\mathrm{Zn}$ (II) ions are brick red balls. 
$(\mathrm{P} \alpha-\mathrm{O} \alpha \beta), 1.606(\mathrm{P} \beta-\mathrm{O} \alpha \beta), 1.583(\mathrm{P} \beta-\mathrm{O} \beta \gamma)$ and $1.630(\mathrm{P} \gamma-$ $\mathrm{O} \beta \gamma) \AA$.

Finally, the work by St. Maurice et al. (see Ref [38] and PDB structure code 3CI4, Ref [3]) reports on the Xray structural characterization of a human-type corrinoid adenosyltransferase, a Mg-ATP-protein system in which $\mathrm{Mg}(\mathrm{II})$ is linked to $\mathrm{P} \alpha, \mathrm{P} \beta$ and $\mathrm{P} \gamma$ (Fig. 5). Note worthy, the triphosphate chain is folded like that found in 1: P...P...P angle being $91^{\circ}$, and a $\mathrm{K}^{+}$cation has contacts with two $\mathrm{O}(\mathrm{P} \gamma)$ oxygen atoms ( 2.677 and $2.877 \AA$ ) and with a $\mathrm{O}(\mathrm{Pa})$ oxygen atom $(2.899 \AA)$. This datum shows the preference of triphosphate chain for $\mathrm{Mg}(\mathrm{II})$ when in competition with $\mathrm{K}(\mathrm{I})$. All the P-O distances compare well with those from low molecular weight metal-nucleotide species.

\section{CONCLUSION}

A number of high accuracy nucleoside triphosphate structures as such or linked to metal ions through the phosphate oxygen atoms are now available from this work and from the literature. Even though the triphosphate chain is a flexible grouping, it is evident that certain structural data like terminal $\mathrm{P}-\mathrm{O}$ and $\mathrm{P}-\mathrm{O}(\mathrm{M})$ distances are fixed within narrow ranges. The analysis for $\mathbf{1}$ and $\mathbf{2}$ from new data sets (namely DS2, DS3 and DS5) showed that changes on hydration of crystals cause significant alteration of conformation at the triphosphate chain and at the ribose system as well as of the pattern of M(II)-triphosphate interactions. The effects from hydration on $\mathrm{M}-\mathrm{O}$ and $\mathrm{P}-\mathrm{O}$ bonds are weaker than those found and reported on the corresponding moieties of $\mathrm{Na}_{2} \mathrm{H}_{2} \mathrm{ATP} \cdot \mathrm{xH}_{2} \mathrm{O}$ species [10]. The higher affinity of $\mathrm{Mg}(\mathrm{II})$ towards phosphates when compared to $\mathrm{Na}(\mathrm{I})$, and $\mathrm{K}(\mathrm{I})$ is such to link the divalent cation just to the triphosphate backbone and exclude any inner sphere interaction to the base and sugar moieties as well as to DPA molecules in $\mathbf{1}$. Thus, the $\mathrm{Mg}(\mathrm{II})$ cation can shift along the triphosphate chain and approach more to one or the other of the phosphate groups, depending on the web of water molecules in 1, or/and on the metal-aminoacid interactions in the enzyme systems, and in turn depending on the need for phosphoryl or pyrophosphoryl transfer. In fact, among the available metallomacronutrients, $\mathrm{Na}(\mathrm{I}), \mathrm{K}(\mathrm{I}), \mathrm{Mg}(\mathrm{II})$ and $\mathrm{Ca}(\mathrm{II})$, in living systems, nature selected $\mathrm{Mg}(\mathrm{II})$ as the cofactor for the vast majority of enzymes that catalyze the breakage of $(\mathrm{P}) \mathrm{O}-\mathrm{P}(\mathrm{O})$ bonds. It appears important that experimental studies via XRD, MQMAS, ESIMS, Raman crystallography like those reported in Refs [10, 39-42], as well as theoretical studies like those reported in Refs 11, 43-45, are more and more performed on $\mathrm{Mg}(\mathrm{II})-\mathrm{NTPs}$ and -NDPs species with the aim to shed light on the mobility of the metal on (di)triphosphate chain, on the role of free and metal bound water molecules, on the role of third molecules (mostly aminoacid residues) able to interact with the metal ions proximal to nucleotides and with nucleotides themselves. The structural role of the second divalent cation in biological systems that catalyze reactions on nucleotides (see for example Refs [46-49]), are worthy of more efforts too, on the basis of structure for 1 and 2 and of recent structures deposited in the PDB.

\section{ACKNOWLEDGEMENTS}

The authors thank MiUR (Ministero dell'Università $\mathrm{e}$ Ricerca, Roma) for funding through the PRIN (Progetto di Rilevante Interesse Nazionale) contract $\mathrm{n}^{\circ} 2004032118$.

\section{SUPPLEMENTARY MATERIAL}

Supplementary material is available on the publishers Web site along with the published article.

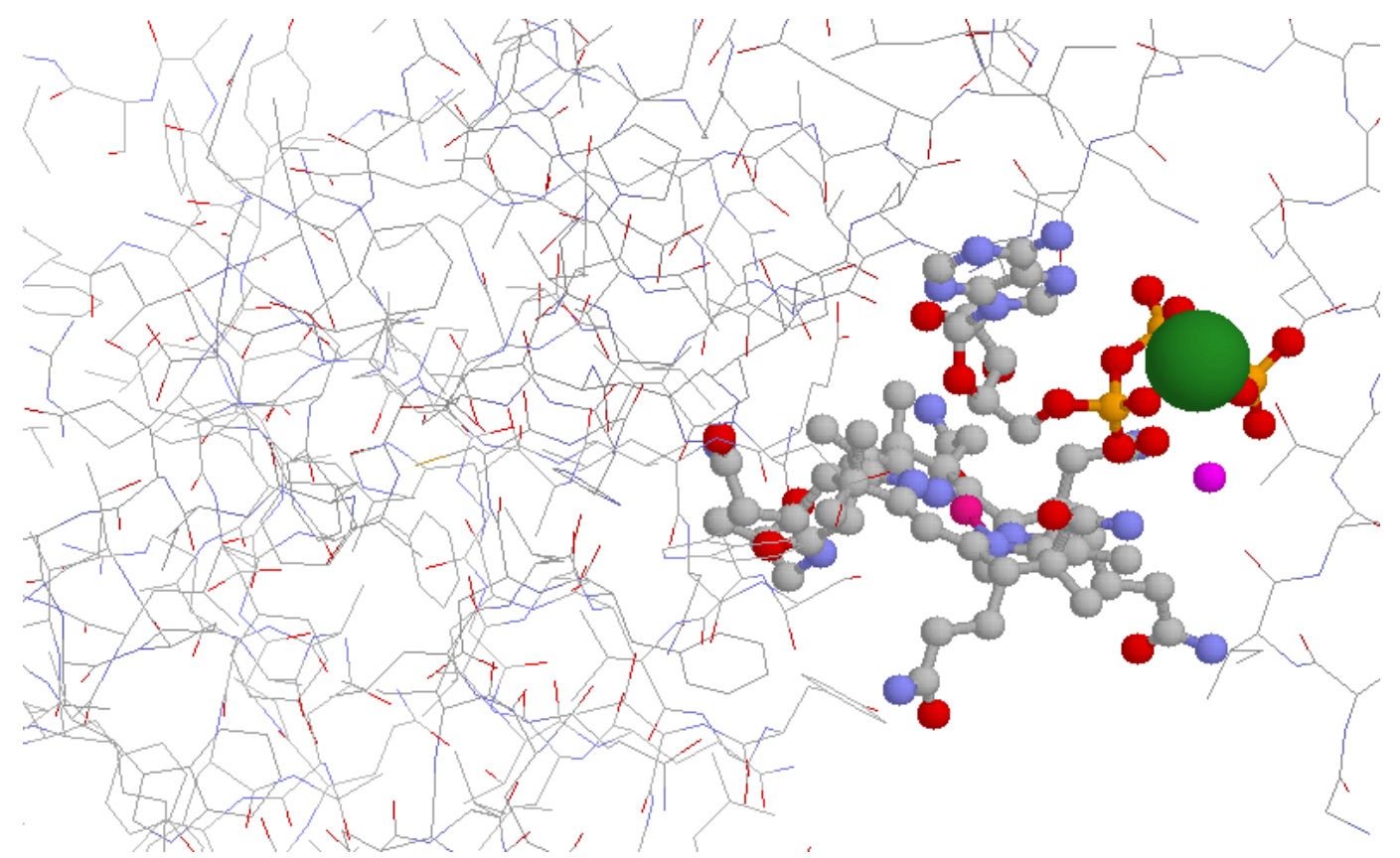

Fig. (5). The diagram shows a portion of the X-ray structure of a human-type corrinoid adenosyltransferase, a Mg-ATP-protein system (see Ref [38] and PDB structure code 3CI4, Ref [3]). The corrinoid moiety and the ATP molecule are color ball \& stick style. The Mg(II) ion is big green ball, whereas the violet small ball in the proximity of triphosphate chain is $\mathrm{K}(\mathrm{I})$ ion and the pink-red small ball inside the ring is cobalt. 


\section{REFERENCES}

[1] Kennard O, Isaacs NW, Coppola JC, et al. Three dimensional structure of adenosine triphosphate. Nature 1970; 225: 333-6.

[2] PubMed, U.S. National Library of Medicine, National Institute of Health, 8600 Rockville Pike, Bethesda, MD 20894. Accessible at http://www.ncbi.nlm.nih.gov/pubmed/

[3] Research Collaboratory for Structural Bioinformatics (RCSB) Protein Data Bank (PDB), Rutgers, the State University of New Jersey, Department of Chemistry and Chemical Biology, 610 Taylor Road, Piscataway, NJ 08854-808. Accessible at http://www. rcsb.org/pdb/home/home.do

[4] Shinoda T, Ogawa H, Cornelius F, Toyoshima C. Crystal structure of the sodium-potassium pump at $2.4 \AA$ resolution. Nature 2009; 459: 446-50.

[5] Kochan G, Pilka ES, von Delft F, Oppermann U, Yue WW. Structural snapshots for the conformation-dependent catalysis by human medium-chain acyl-coenzyme A synthetase ACSM2A. J Mol Biol 2009; 388: 997-1008.

[6] Trinh CH, Asipu A, Bonthronb DT, Phillips SEV. Structures of alternatively spliced isoforms of human ketohexokinase. Acta Cryst Sec D, Biol Crystallogr 2009; D65: 2001-11.

[7] Grycova L, Sklenovsky P, Lansky Z, et al. ATP and magnesium drive conformational changes of the $\mathrm{Na}^{+} / \mathrm{K}^{+}$-ATPase cytoplasmic headpiece. Biochem Biophys Acta 2009; 1788: 1081-91.

[8] Fischmann TO, Smith CK, Mayhood TW, et al. Crystal structures of MEK1 binary and ternary complexes with nucleotides and inhibitors. Biochemistry 2009; 48: 2661-74

[9] Saenger W. In: Cantor CR Ed. Principles of nucleic acid structure. Springer Advanced Texts in Chemistry. Berlin: Springer-Verlag 1984.

[10] Sugawara Y, Kamiya N, Iwasaki H, Ito T, Satow Y. Humiditycontrolled reversible structure transition of disodium adenosine 5'Triphosphate between dihydrate and trihydrate in a single crystal state. J Am Chem Soc 1991; 113: 5440-5.

[11] Arabi AA, Matta CF. Where is electronic energy stored in adenosine triphosphate? J Phys Chem A 2009; 113: 3360-8.

[12] Cini R, Sabat M, Sundaralingam M, et al. Interaction of adenosine 5'-Triphosphate with metal ions: X-ray structure of ternary complexes containing $\mathrm{Mg}(\mathrm{II}), \mathrm{Ca}(\mathrm{II}), \mathrm{Mn}(\mathrm{II}), \mathrm{Co}(\mathrm{II}), \mathrm{ATP}$, and 2,2'Dipyridylamine. J Biomol Struct Dyn 1983; 1: 633-7.

[13] Cini R, Burla MC, Nunzi A, Polidori G, Zanazzi PF. Preparation and physico-chemical properties of the ternary complexes between adenosine 5'-triphosphoric acid, bis(2-pyridyl)amine and divalent metal iONS. Crystal and Molecular Structures of the Compounds containing $\mathrm{Mg}(\mathrm{II})$ and $\mathrm{Ca}(\mathrm{II})$. J Chem Soc Dalton Trans 1984; 11: 2467-76.

[14] Cambridge Structural Data Base. The Cambridge Crystallographic Data Centre. 12 Union Road, Cambridge, CB2 1EZ, UK.

[15] Cini R, Marzilli LG. Exploitation of crystalline architecture and solution data in the rational preparation of novel mixed-metal ATP complexes. Inorg Chem 1988; 27: 1855-6.

[16] Sheldrick GM. SHELXS-97 programs for the solution of crystal structures, Germany: University of Göttingen, Göttingen 1997.

[17] Sheldrick GM. SHELXL-97 programs for the refinement of crystal structures, Germany: University of Göttingen, Göttingen 1997.

[18] Farrugia LJ. WinGX an integrated system of windows programs for the solution, refinement and analysis of single crystal x-ray diffraction data, version 1.64.05, University of Glasgow, Glasgow, UK 1999-03.

[19] Farrugia LJ. Win $G X$ suite for small-molecule single-crystal crystallography. J Appl Crystallogr 1999; 32: 837-8.

[20] Nardelli M. PARST-97, A system of computer routines for calculating molecular parameters from results of crystal structure analyses, University of Parma 1997.

[21] Johnson CK, Burnett MN. ORTEP-3 for Windows, Oak Ridge National Laboratory, 1998. 32-bit Implementation by Farrugia, L.J. University of Glasgow, Glasgow, UK 1999.

[22] Oxford Instruments, Tubney Woods, Abingdon, Oxfordshire, OX13 5QX, UK.

[23] Cosier J, Glazer AM. A nitrogen-gas-stream cryostat for general Xray diffraction studies. J Appl Crystallogr 1986; 19: 105-10.

[24] Hooft RWW. COLLECT data collection software, Nonius BV, Delft, The Netherlands 1998.
Otwinowski Z, Minor W. In: Carter CW, Sweet RM, Eds., Macromolecular Crystallography, Part A; Methods in Enzymology. San Diego, CA, U.S.A: Academic Press 1997; vol 276: pp. 307-26.

[26] Sheldrick GM. SADABS, program for absorption correction, Germany: University of Göttingen, Göttingen 2003.

[27] Sabat M, Cini R, Haromy T, Sundaralingam M. Crystal structure of the $\alpha, \beta, \gamma$-tridentate manganese complex of adenosine 5'Triphosphate cocrystallized with 2,2'-Dipyridylamine. Biochemistry $1985 ; 24: 7827-33$.

[28] Bazzicalupi C, Bencini A, Bianchi A, et al. Polyfunctional binding of Thymidine 5'-Triphosphate with a synthetic polyammonium receptor containing aromatic groups. Crystal structure of the nucleotide-receptor adduct. J Am Chem Soc 2008; 130: 2440-1

[29] Kato M, Sah AK, Tanase T, Mikuriya M. Transformation of a tetranuclear Copper(II) complex bridged by sugar phosphates into nucleotide-containing $\mathrm{Cu}_{4}$ aggregations. Eur J Inorg Chem 2006; 12: 2504-13.

[30] Cini R, Pifferi C. Supramolecular networks via hydrogen bonding and stacking interactions for adenosine 5 '-diphosphate. Synthesis and crystal structure of diaqua $\left(2,2^{\prime}: 6^{\prime}, 2^{\prime \prime}\right.$-terpyridine $)$ copper(II) (adenosine 5'-diphosphate(3-))(2,2':6',2"-terpyridine)rameate(II) $\left(\mathrm{H}_{2}\right.$ adenosine 5'-diphospate(1-)) hexadecahydrate and density functional geometry optimization analysis of copper(II)- and zinc(II)-pyrophosphate complexes. J Chem Soc Dalton Trans 1999; 5: 699-710.

[31] Cini R, Chindamo D, Catenaccio M, Lorenzini S, Marcolongo R Density functional geometry optimization and energy calculations of Calcium(II)-triphosphate complexes. Polyphosphates as possible dissolving agents for Calcium Pyrophosphate Dihydrate crystals in chondrocalcinosis disease. J Biomol Struct Dyn 2000; 18: 15568.

[32] Thoden JB, Holden HM, Firestine SM. Structural analysis of the active site geometry of $\mathrm{N}^{5}$-Carboxyaminoimidazole ribonucleotide synthetase from Escherichia coli. Biochemistry 2008; 47: 1334653.

[33] Mou T-C, Masada N, Cooper DMF, Sprang SR. Structural basis for inhibition of mammalian adenylyl cyclase by Calcium. Biochemistry 2009; 48: 3387-97.

[34] Bondi A. Van der Waals volumes and radii. J Phys Chem 1964; 68: 441-51.

[35] Regni CA, Roush RF, Miller DJ, Nourse A, Walsh CT, Schulman BA. How the MccB bacterial ancestor of ubiquitin E1 initiates biosynthesis of the microcin C7 antibiotic. EMBO J 2009; 28: 1953-64

[36] Evans RJ, Davies DR, Bullard JA, et al. Structure of PolC reveals unique DNA binding and fidelity determinants. Proc Natl Acad Sci USA 2008; 105: 20695-700.

[37] Jönsson TJ, Murray MS, Johnson LC, Todd Lowther W. Reduction of cystein sulfinil acid in peroxiredoxin by sulfiredoxin proceeds directly through a sulfinic phosphoryl ester intermediate. J Biol Chem 2008; 283: 23846-51.

[38] St. Maurice M, Mera P, Park K, Brunold TC, Escalante-Semerena JC, Rayment I. Structural characterization of a human-type corrinoid adenosyltransferase confirms that coenzyme $\mathrm{B}_{12}$ is synthesized through a four-coordinate intermediate. Biochemistry 2008; 47 : 5755-66.

[39] Nausner M, Brus J, Häubl M, Müller N, Schoefberger W. Characterization of the sodium binding sites in microcrystalline ATP by ${ }^{23} \mathrm{Na}$-solid-state NMR and $a b$ initio calculations. Inorg Chim Acta 2009; 362: 1071-7.

[40] Grant CV, Frydman V, Frydman L. Solid-state ${ }^{25} \mathrm{Mg}$ NMR of a Magnesium(II) Adensosine 5'-Triphosphate complex. J Am Chem Soc 2000; 122: 11743-4

[41] Wyttenbach $\mathrm{T}$, Bowers MT. Intermolecular interactions in biomolecular systems examined by mass spectrometry. Ann Rev Phys Chem 2007; 58: 511-33.

[42] Gong B, Chen Y, Christian EL, et al. Detection of inner sphere interactions between magnesium hydrate and the phosphate backbone of the HDV ribozyme using raman crystallography. J Am Chem Soc 2008; 130: 9670-2.

[43] Florián J, Baumruk V, Štrajbl M, Bednárová L, Štěpánek. IR and raman spectra, conformational flexibility, scaled quantum mechanical force fields of sodium dimethyl phosphate and dimethyl phosphate anion. J Phys Chem 1996; 100: 1559-68. 
[44] Matta CF, Arabi AA, Keith TA. Atomic partitioning of the dissociation energy of the $\mathrm{P}-\mathrm{O}(\mathrm{H})$ bond in hydrogen phosphate anion $\left(\mathrm{HPO}_{4}{ }^{2-}\right)$ : disentangling the effect of $\mathrm{Mg}^{2+}$. J Phys Chem A 2007; 111: 8864-72.

[45] Burke RM, Dessent CEH. Effect of cation complexation on the structure of a conformationally flexible multiply charged anion: stabilization of excess charge in the $\mathrm{Na}^{+}$.Adenosine $5^{\prime}$ Triphosphate dianion ion-pair complex. J Phys Chem A 2009; 113: 2683-92.

[46] Su L, Cukier RI. An enhanced molecular dynamics study of HPPK-ATP conformation space exploration and ATP binding to HPPK. J Phys Chem A 2009; 113: 2025-35.
[47] Shaffer J, Adams JA. An ATP-linked structural change in protein kinase a precedes phosphoryl transfer under physiological magnesium concentrations. Biochemistry 1999; 38: 5572-81.

[48] Saylor P, Wang C, Hirai TJ, Adams JA. A second magnesium ion is critical for ATP binding in the kinase domain of the oncoprotein v-Fps. Biochemistry 1998; 37: 12624-30.

[49] Larsen TM, Benning MM, Rayment I, Reed GH. Structure of the Bis $\left(\mathrm{Mg}^{2+}\right)-\mathrm{ATP}-\mathrm{Oxalate}$ Complex of the rabbit muscle pyruvate kinase at $2.1 \AA$ resolution: ATP binding over a barrel. Biochemistry 1998; 37: 6247-55.

(C) Tamasi et al.; Licensee Bentham Open.

This is an open access article licensed under the terms of the Creative Commons Attribution Non-Commercial License (http://creativecommons.org/licenses/by$\mathrm{nc} / 3.0 /$ ) which permits unrestricted, non-commercial use, distribution and reproduction in any medium, provided the work is properly cited. 